\title{
Ecological and economic assessment of sectoral agricultural technologies
}

\author{
Kheda Murtazova * \\ Chechen State University named after A.A. Kadyrov, 364024, 32, Sheripova st., Grozny, \\ Russian Federation
}

\begin{abstract}
The urgency of the fuel and energy problem determines the need for rational energy consumption in all sectors of the economy, including agriculture. A comprehensive cross-sectoral approach is needed to address the issues of systemic management of energy conservation in agriculture and to substantiate rational measures of economic support for the introduction of energy-saving technologies, equipment and projects from the state. The main advantage of the energy-economic assessment is that its application allows comparison in uniform units of measurement (regardless of the historical period or state, the current market situation) the costs of growing plants or servicing animals with production results and are mainly of national strategic importance.
\end{abstract}

\section{Introduction}

Throughout the history of Russia, the land issue was and still remains one of the main ones. At the present stage of the development of society, when new production relations are being formed, this issue is paramount in the reform policy. In the socio-economic development of the country, one of the priority places is taken by increasing the efficiency of the agrarian economy. This criterion is important for characterizing the economic wellbeing of the country, since it is associated with the satisfaction of the vital needs of a person - the provision of adequate nutrition. However, among all the reform actions, it was the changes in the agrarian sector of the country's economy that turned out to be the most difficult to implement. It should be especially noted that state support for agricultural producers is insufficient, which, as a rule, is not allowed by any economically developed country in the world.

Since the 1930s, in our country, the economic efficiency of agricultural production has been sacrificed to political "expediency". According to a number of scientists, the creation of environmentally stable production in the agro-industrial complex, as a rule, is

\footnotetext{
*Corresponding author: fu.ggni@mail.ru
} 
accompanied by a significant increase in the economic efficiency of production. This is due to the fact that increasing the efficiency of the use of natural resources, including land, is inextricably linked with environmental stabilization in the industrial sector of the agroindustrial complex. The use of land resources has a number of features. These include the following: the spatial limitation of land resources, the multi-purpose nature of their use, immobility - that is, they are not subject to movement as needed, some limited options for land use, since the land use process is divided into two types - intensive and extensive. The land reveals its essence as the main means of production through soil fertility. The preservation of soil fertility of lands and its rational use in economic activities is of economic and social importance. The economic significance of soil fertility is determined by the fact that, being a natural condition for the intensification of agriculture, it contributes to an increase in yields and gross harvests of agricultural crops, and thus affects the economic well-being of an individual commodity producer, economy, region and country as a whole. Distinguish between natural, artificial and economic fertility. The initial basis of agriculture is the natural fertility of the soil. Natural and artificial soil fertility are integrated into the economic one. They share the potential economic fertility - the maximum possible satisfaction in agricultural production, and the actual one, which depends on the level and degree of land use. The ratio of the actual economic fertility to the potential indicates the level of use of land resources as the main means of production.

The use of the productive force of soil fertility makes it possible in the production process to obtain one or another effect with a certain degree of efficiency. In recent years, in the scientific literature, along with the economic efficiency of the use of land resources, the concepts of environmental, social and technological efficiency have been considered. For land, as a resource, a plurality of meanings and modes of functioning are characteristic. An integrated multidimensional approach to the concept of "land resources" serves as a necessary cognitive tool that allows you to embrace and present in unity, at first glance, disparate, but in fact, objectively interrelated aspects of the functioning of this natural component [1]. In the economic aspect, the land is understood as a means of production, which has a number of specific features that distinguish it from others. These features, in addition to those listed above, are as follows: - land is not the result of human labor, and therefore has no value; - land cannot, in contrast to other means of production, be quantitatively increased or qualitatively modified, it cannot be replaced by other, more perfect means of production; - all means of production wear out in the process of use, while the land, with proper use, not only does not lose its properties, but can improve them.

Land is a specific subject of market relations. Firstly, not all of the land fund passes through the purchase and sale system, for example, specially protected territories and reserve lands are excluded from this area. Second, land is mortgaged, sold, bought and leased under certain conditions. In this, land resources are fundamentally different from other means of production that can be sold, always and without any special limiting circumstances [1]. In the process of achieving certain goals, we exploit land resources as one of the components of the natural complex, and production and society create conditions for their functioning, which include the need to ensure high efficiency. Efficiency is associated with an effect that is considered as an action, a consequence of any cause, activity, as a result of the development of a process. In the production process, natural substances are consumed, which must be replaced back. The ratio of consumed to received substances determines the environmental efficiency. The use of natural and material resources allows you to create new products that have value. The substances introduced into the natural complex under the project generate capital costs and annual costs. The combination of the cost of production and costs reflects the economic efficiency of land use. Thus, economic efficiency reflects the degree of implementation of production 
relations and is measured by a system of value indicators that characterize the efficiency of production. Technological efficiency characterizes the use of production resources by comparing actual data with the standard level (yield, productivity, agricultural production in comparable prices per 100 hectares of conventional arable land, per one average annual worker, per 100 rubles of agricultural production assets). Social efficiency characterizes social development, the level of which is determined by the degree of achievement of the normative standard of living and is measured as the ratio of the increase in the time of active life to the time spent on obtaining it.

Since an increase in the level of land use is an objective necessity and a condition for the progressive development of society, and there is practically no limit to this process, insofar as the concepts of rational and efficient use of land have been and remain relevant.

Roughly $40 \%$ of the land surface is currently used for food production, indicating that agriculture is currently the predominant land use [1]. Agricultural intensification and expansion is widely regarded as a policy option to improve food security and support human development [2]. However, it is widely recognized that agriculture is often associated with a wide range of negative environmental impacts, which may include increased greenhouse gas (GHG) and ammonia emissions; eutrophication; the use of toxic herbicides and pesticides; depletion of fresh water; and increased soil compaction, depletion and erosion [3-5]. In particular, agriculture is recognized as a leading driver of biodiversity loss, which mainly occurs as a result of the transformation of natural habitats into agricultural systems. Therefore, there is an urgent need to reduce the impact of food production on biodiversity, which can potentially be achieved by changing food production and consumption patterns, as well as by combining conservation, sustainable management and restoration of the environment [6]. While many methods and strategies are already available that can help achieve this goal, there is a particular need to scale them up from local to landscape or regional [6].

\section{Methods}

The main methodological principles in the assessment of agricultural production should be the following: a systematic approach; consideration of environmental impacts; taking into account the time period during which natural processes are carried out. The economic effect of environmental protection measures is expressed in the amount of the prevented annual economic damage from environmental pollution (for single-purpose environmental protection measures) or the sum of prevented losses and the annual increase in income from improving production results due to environmental protection measures. from environmental pollution is equal to the difference between the calculated values of damage that took place before the implementation of the measure under consideration, and the residual damage after the implementation of this measure.

Ecological and economic efficiency characterizes the economic efficiency of a set of measures related to improving the quality of land, the natural environment, and optimizing the structure of the agroecosystem. This type of efficiency reflects the effectiveness of environmental costs associated with increasing soil fertility, protecting land from erosion, pollution, improving the ecological and reclamation state of land, protecting the natural environment. Criteria of ecological and economic efficiency are the degree of improvement of the ecological state of the agro-ecosystem, increasing fertility of soils, their cultivation, reduction of pollution of land, which finds expression in additional production and prevented environmental damage to the natural environment. Environmental damage in relation to soil fertility is characterized by natural and cost indicators. The first include: the 
area of eroded lands: the mass of lost organic matter, phosphorus, potassium; the mass of lost humus and nutrients in terms of organic and mineral fertilizers; area of land withdrawn from agricultural use. The proposed methodological approach to assessing the economic efficiency of farming on eroded and erosion-hazardous lands, in contrast to the existing industry methods, provides for the consideration of the ecological component of the effect of land use.

The basis for rational land use and protection of land resources is the achievement of a complex of economic, social, environmental and other goals of society. The interconnection and consistency of all these goals is possible with a systematic approach to the analysis of the effective use of land resources. It is very important to find out the degree of correspondence or inconsistency between the current state of the entire production system of the agro-industrial complex and the goals that economics traditionally singled out: production of agricultural products; social reproduction of the population; reproduction of land and natural potential [2]. This will allow us to outline the ways of implementing measures to bring it into a state of equilibrium.

\section{Results}

Currently, the need for environmental and economic assessment of natural resources in our country is recognized at the highest level. In the Environmental Doctrine of the Russian Federation, as one of the main economic and financial mechanisms for ensuring rational use of natural resources and environmental protection, it is envisaged to include in economic indicators the full and ever-increasing value of natural objects and environmental services and take them into account when making management decisions. In this regard, the role of the ecological and economic assessment of natural resources as the main element of the system of state management of the natural resource potential of the territory of the Russian Federation is growing.

The largest percentage of agricultural land in the Chechen Republic as a whole falls in Shelkovskaya (24.9\%), Naursky (19.2\%) and Grozny (11.4\%) districts. The availability of land of this category in other districts averaged $2.1 \%$. Of the total area of agricultural land in the aforementioned regions, agricultural land occupies $86.6 \%, 83.6 \%$ and $88.5 \%$, respectively. At the same time, it should be noted that in the Shelkovsky and Naursky regions, due to the natural and climatic conditions of these regions, as well as their location in the semi-desert and steppe zones, the main share in agricultural land is occupied by pastures (in the Shelkovsky region - 80.7\%, Naursky district - 65.6\%), while in the Grozny district (forest-steppe zone) pastures occupy $24.5 \%$ of all agricultural land in the district, arable land $-69.8 \%$.

Unlike some other constituent entities of the Russian Federation, agricultural lands in the Chechen Republic seized from land users due to violation of land legislation or for any other reason were not transferred to the category of reserve lands, but returned to the balance of previous land users (in particular - state farms). In this regard, there is no decrease in agricultural land due to the transfer to the category of reserve land.

Allocation of agricultural land for non-agricultural purposes in the Chechen Republic is extremely rare and in exceptional cases. In particular, agricultural land is allocated for service stations and gas stations, as well as for the construction of cafes, markets, etc., mainly along highways and on the outskirts of settlements. However, even in such cases, the category of land does not change, the area of the allotted plots is measured in square meters. 
There are also unused lands in the composition of agricultural land. Basically, this applies to the lands of state enterprises. The main reasons for not using land is their violation as a result of hostilities - digging trenches and trenches, mining, deployment of military units and the restriction of access to them in this regard. Often the reason for not using the land of state-owned enterprises is the complete or partial absence of a material and technical base. Due to the objectivity of non-use of land, constructive measures in relation to these land users (seizure, transfer to another category or land redistribution fund) are not applied.

To date, there are no objective methods to assess natural resources and conditions, there are no unified approaches to their determination, therefore, there is a certain difficulty in localizing a natural resource as an object of environmental and economic assessment. At the same time, the ecological and economic assessment of natural resources (objects) is a monetary expression of their value in fixed socio-economic conditions of production under given modes of nature management and environmental restrictions on economic and other activities. The ecological and economic assessment of natural resources is carried out with the aim of: effective management of natural resources; accounting for the cost of natural resources as part of the country's economic assets; substantiation of strategies, long-term and medium-term plans for the socio-economic development of the Russian Federation and its subjects; inclusion of indicators of environmental and economic assessment of natural resources in the system of socio-economic relations in society; solving the whole range of issues related to the rational use of natural resources.

\section{Discussion}

The performed assessment of the natural resource potential of the developed territories shows that the amount of damage to the natural resource potential depends on:

- from reserves of natural resource potential;

- the degree of technogenic transformation of natural landscapes;

- territory affected by anthropogenic transformations;

- period (time) of technogenic impact on ecosystems.

The performed assessment of the natural resource potential of the developed territories shows that the amount of damage to the natural resource potential depends on:

- from reserves of natural resource potential;

- the degree of technogenic transformation of natural landscapes;

- territory affected by anthropogenic transformations;

- period (time) of technogenic impact on ecosystems.

Economic calculations show that the costs of soil reclamation are fully paid off when the contaminated land is returned to agricultural production using it for arable and pasture land. Surface layers of air are an indirect source of hydrocarbons entering soil and water. The light fractions of hydrocarbons formed on land as a result of refining and using oil enter the air basin and, scattering, are gradually carried over considerable distances, and then, together with atmospheric precipitation, they enter both the surface of the earth and in the water area.

State monitoring of the state of land resources shows that the country continues, with a high rate of deterioration in the quality of land resources

It seems to us that it will be problematic to ensure the country's food security without a decision, and without delay, in the not too distant future. Sustainable development of agroindustrial production is possible only on the basis of optimizing the use of natural resources in the industry with a constant, and expanded reproduction of natural fertility, this provides 
for the transition to the path of greening the entire agro-industrial production. In the Chechen Republic, the practice of using chemical fertilizers and means of combating agricultural pests is practically excluded, therefore, the products produced are environmentally friendly. For the successful conduct of agricultural production, it is necessary to conduct a comprehensive survey of the entire soil and land resource, only then it will be possible to speak more objectively about the geoecological state of the agricultural landscapes of the Chechen Republic, which have undergone very serious anthropogenic pressure for many years. This has seriously changed the natural balance of components in the ecosystem, degradation processes such as salinization, chemical pollution, erosion processes, compaction of the soil layer and many others are actively taking place, which, naturally, reduce primarily the yield of agricultural crops. One of the most negative consequences of agricultural production without observing all norms and agricultural technologies leads to a decrease, and often losses, if erosion processes occur, of natural fertility.

\section{Conclusion}

Environmental and economic efficiency characterizes the aggregate economic performance of the agricultural production process, taking into account its impact on the environment, that is, taking into account the costs associated with the elimination or prevention of its pollution and destruction, as well as losses of agricultural products associated with the deterioration of the environmental situation.

\section{References}

1. I.A. Bayrakov, R.A. Gakaev, Geoecological foundations of the use of natural resources and environmental protection in the Chechen Republic, 58 (2018)

2. A.A. Bokarev, Green Investments in Russia: Search for Priority Areas (2017)

3. T.V. Zakharova, «Green» economy as a new course of development: global and regional aspects (2018)

4. Federal national project «Ecology» (2018)

5. S. G. Tyaglov, Modern aspects of the development of the «Green economy» in the Russian Federation, 104 (2017)

6. M.V. Onishchenko, The role of the state in the development of the «Green Economy», $560(2020)$

7. O.D. Ermolenko, Problems and prospects for the development of viticulture on the basis of state support, 362 (2020)

8. V.I.Kiryushin, Ecological foundations of agriculture, 267 (2000)

9. H. Buller, G.A.Wilson G.A., Agri-environmental policy in the European Union: Ashgate. Aldershot, 291 (2020)

10. L. Lohr, T. Park, L. Higley,Farmer risk assessment for voluntary insecticide reduction (2019) 